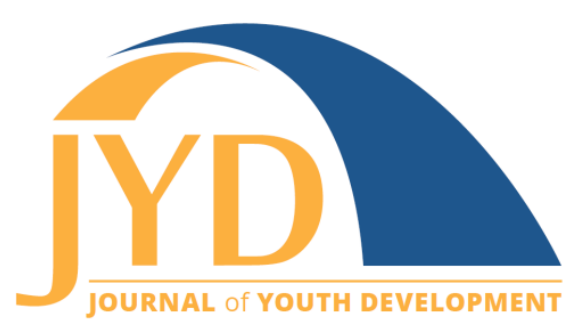

http://jyd.pitt.edu/ | Vol. 15 Issue 1 DOI 10.5195/jyd.2020.937 | ISSN 2325-4017 (online)

\title{
Foundations for the Future: Building an Integrated, Cohesive Field of Youth Development
}

\author{
Lynne M. Borden \\ University of Minnesota \\ Imborden@umn.edu \\ Jaime Ballard \\ University of Minnesota \\ roger324@umn.edu \\ Louisa Michl-Petzing \\ University of Minnesota \\ mich1022@umn.edu \\ Michael Conn \\ Student Research Foundation \\ michaelconn.ny@gmail.com

\section{Casey D. Mull} \\ University of Georgia Extension \\ mullcd2@uga.edu \\ Michele Wilkens \\ NAA Board of Directors \\ michelewilkens1@gmail.com
}

\section{Abstract}

The field of youth development continues to evolve and grow, as many professionals (e.g., social workers, health care workers, public health workers, etc.) have begun to recognize the role youth development plays in their daily work. However, the challenge now is to properly identify the youth development-related work of these professionals, in order to appropriately support and resource the workforce to ensure their success with youth. The current article concludes this special issue on the Youth Development Workforce, with insights from key leaders in the field of youth development on the

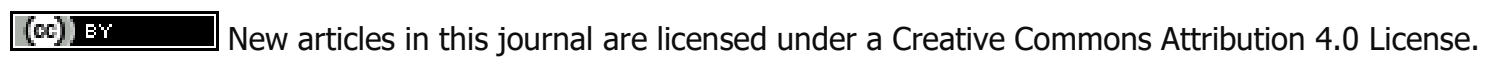
This journal is published by the University Library System, University of Pittsburgh and is cosponsored by the University of Pittsburgh Press. The Journal of Youth Development is the official peer-reviewed publication of the National Association of Extension 4-H Youth Development Professionals and the National AfterSchool Association. 
Foundations for the Future

strengths and challenges that the field will face as it transforms. This article, in combination with the prior articles in this special issue, reflects the current efforts of the youth development workforce that acts as a foundation for the future of the field.

Key words: youth development, youth workers, youth programs

\section{Introduction}

Key leaders in the field of youth development offer a sentiment of hope and endless possibilities for the individuals who work with and on behalf of young people. The field continues to evolve and grow, with many professionals (e.g., social workers, health care workers, teachers, and others) beginning to recognize the role of youth development principles in their daily work. However, the challenge becomes one of not only identifying the theoretical premise of youth development, but also the identification of the work done on behalf of youth. The field of youth development is also tasked with defining and rationalizing its own inclusionary or exclusionary criteria: Who is considered part of the field? Do those professionals view themselves as within the field? What type of work is and is not considered youth development work?

The articles included in this issue illustrate the many strengths and successes in the field of youth development and offer a better understanding of the professionals who have chosen to work with and on behalf of young people. Regardless of their chosen role (e.g., after-school provider, youth coordinator, youth homeless shelter worker, or other), every professional is challenged to build a positive relationship with each young person to foster their development and successful transition to young adulthood (See Hall this issue). Moreover, organizations are striving to increase the knowledge and skills of these workers to ensure the programs being conducted are of the highest quality (See McNamara, DeMand, McGovern, \& Akiva this issue). Together these articles lay a foundation from which to consider the future of the field. We conclude this issue by providing a vision of the future from key leaders in the field as they offer insights into the opportunities for progress as well as the challenges facing those who are laying the foundational bricks.

\section{Positive Youth Development}

For more than 100 years, adults have intentionally focused on creating environments designed to enhance a young person's positive development (Borden, Schlomer, \& Wiggs, 2011). This focus on generating opportunities for young people was a result of two major social changes: 


\section{Foundations for the Future}

the decreased number of children needed in the workforce and the enactment of compulsory education laws (Halpern, 2002). Such societal change saw a rise in organized programs, including the work of Jane Addams and the settlement house workers whose job it was to work with poor children to learn about life in America (Walker, Walker, \& Gambone, 2011). The Young Men's Christian Association (YMCA) in the 1800s, followed by Boys Clubs in 1860 (later to become Boys and Girls Clubs), 4-H Youth Development, Girl Scouts of the U.S.A., and others (Borden, Schlomer, \& Wiggs, 2011) saw an opportunity to work directly with young people using their newly available discretionary time. Early on, these youth-focused programs followed a deficit model, as they attempted to "fix" youth participants by keeping them out of trouble and helping them become better citizens. While such programming may have prevented some negative behaviors, it did not prepare youth to successfully transition into young adulthood. Given the limitations of this model, the principles of positive youth development emerged as the theoretical foundation to the field of youth development.

In 2001, Benson and Pittman edited, Trends in Youth Development: Visions, Realities, and Challenges. This volume reflected a decade of youth development thinking, with contributions from leaders in employment, child welfare, juvenile justice, the policy arena, and others, identifying the integration of key youth development principles across and within diverse organizations. Further, in 2017, Leman, Smith, and Peterson stated, "over the past 30 years, positive youth development (PYD) has emerged as an important strand of the applied development science," (p. 1039). The continued growth in positive youth development has led other fields to see the value of this developmental process and to incorporate it into their own work. For instance, the influence of positive youth development on the field of mental health is seen in D. L. Evans and colleagues' (2005) inclusion of a chapter entitled "The Positive Perspective on Youth Development" in their book Preventing Adolescent Mental Health Disorders: What We Know and We Don't Know: A Research Agenda for Improving the Mental Health of Our Youth. Similarly, Chapin Hall released a report by Barton and Butts (2008) entitled, Building on Strength: Positive Youth Development in Juvenile Justice Programs, showing the influence of PYD on the field of juvenile justice. As multiple disciplines, including mental health, education, social work, sports management, and others have incorporated the key principles of positive youth development into their work, we have seen the evolution of a field that is cross-sector and highly diverse. We now turn to key leaders in youth development to incorporate these varied perspectives and provide their assessment of the field as a whole. 


\section{Key Leader Interviews}

Key leaders within the field of youth development were identified and represent past and present presidents of youth-serving organizations, professors in youth fields, and directors of research and support programs for youth work organizations. Each has fought battles for youth and for youth development and has a clear view of the history and trajectory of youth work.

Table 1. Identification of Key Leaders in the Field of Youth Development

\begin{tabular}{|l|l|}
\hline Name & Position \& organization \\
\hline Dale A. Blyth, PhD & $\begin{array}{l}\text { Professor Emeritus and former Howland Endowed Chair in } \\
\text { Youth Development Leadership, University of Minnesota }\end{array}$ \\
\hline Dana Fusco, PhD & Professor and Department Chair, CUNY York College \\
\hline Pam Garza, BA (2) & Consultant, many youth development organizations \\
\hline Ellen Gannet, MEd and Georgia Hall, PhD & $\begin{array}{l}\text { Senior Strategist and former Director (Gannet) and } \\
\text { Director and Senior Research Scientist (Hall), National } \\
\text { Institute on Out-of-School Time, Wellesley College }\end{array}$ \\
\hline Stephanie J. Hull, PhD & President \& CEO, Girls, Inc. \\
\hline Jack E. Kosakowski, BBA & President \& CEO, Junior Achievement USA \\
\hline Karen J. Pittman, MA & $\begin{array}{l}\text { Co-Founder, President \& CEO, The Forum for Youth } \\
\text { Investment }\end{array}$ \\
\hline Jane Quinn, MA & $\begin{array}{l}\text { Recently retired as Director, National Center for } \\
\text { Community Schools, Children's Aid }\end{array}$ \\
\hline Joyce A. Walker, PhD & $\begin{array}{l}\text { Professor Emerita, Center for Youth Development, } \\
\text { Minnesota Extension Service, University of Minnesota }\end{array}$ \\
\hline
\end{tabular}

These key leaders received a survey asking their perceptions of the greatest opportunities and challenges facing the field of youth development. They were further asked to provide examples of how their organizations utilized these opportunities and addressed these challenges. Additional questions addressed the role of national policy, shared and specific goals and values in the various contexts of youth work, and how internal and external resources are utilized to benefit youth and society. In qualitatively analyzing the data received, the following themes emerged as key considerations for the field of youth development. 


\section{Recognition of Youth Work as a Profession}

As highlighted throughout the articles included in this special issue, the complexity of the field of youth development within the United States creates both opportunities and challenges from which to build a profession. Youth work is highly varied, serving young people from early childhood through young adulthood and with roles that include after-school program staff, camp counselors, coaches, teen shelter staff, caseworkers, faith-based youth program staff, and others. Youth work is done across a wide variety of school- and community-based settings in programs that occur after school, on weekends, and during the summer. It is additionally offered by a diverse set of public, non-profit, and for-profit organizations. The young people served are highly diverse socially, economically, culturally, ethnically, and educationally with widely contrasting opportunities and supports. Given this huge variability across the nature, setting, and participants of youth programming, youth development has lacked recognition as an integrated field, and thus, youth workers are often not perceived as part of a unified profession. In other words, there is a lack of understanding because the general public does not have a clear vision of what youth workers do.

Not surprisingly, then, the most central theme from key leader interview responses was the resounding need for recognition of youth work as a profession. For example, Dana Fusco stated:

Youth work, with a long though disparate and disjointed history as a "field, "is no longer a practice known by its name, endorsed by any national professional association, or captured in a common academic discipline. Youth programs, once known as "youth work," have mostly closed and/or are operating with severe structural deficits.

Georgia Hall also reflected on the need for recognition of youth workers.

The field needs a national approach to youth workers (policy, legislation, funding) that includes all sectors of the field-residential, after-school, schoolage care, $21^{\text {st }}$ Century Community Learning Centers, juvenile justice-as a blended career. Youth worker might become an umbrella term and then we work to break down the barriers that keep the field divided/in silos.

According to key leaders, the primary barriers to advancing youth work as a unified field are the absence of national youth policy, a fractured field of siloed youth work, and the lack of value and support for youth work positions. Each barrier is discussed below. 


\section{Lack of National Youth Policy}

The United States lacks national infrastructure or policy to coordinate the federal systems serving youth (Pozzoboni \& Kirshner, 2016). There are 21 federal departments and agencies that serve youth. Though an Interagency Working Group on Youth Programs (IWGYP) was formed in 2008 to promote collaboration among these groups, these efforts are still in progress (youth.gov). IWGYP recently created the Pathways for Youth report, which is a "first step to help the partners address their common goals for youth," (IWGYP; 2016, p. 3). Nearly every leader interviewed (seven of the nine) noted the lack of a national youth policy as a challenge. Fusco underscored how this reflects underlying values, or the lack thereof:

It is quite difficult, at this point in our nation's history, to begin with a discussion about youth workers when it is not clear this nation has embraced youth work as a practice, as a policy, as a profession, or even youth as a worthy target for services.

Dale Blyth further described the absence of necessary systems to coordinate the efforts of youth-serving professionals:

Many European countries have departments and policy focused on youth-often extending to the mid- to late-20s-and often engaging youth proactively in their creation, monitoring, and refinement. The absence of a youth policy, and even fundamental agreement on the rights of young people to be engaged, means we lack key unifying tools for advancing the field and enhancing our impact on youth and communities. Both policy work and the potential resources that come with them provide tools that could help unite efforts and deal with the challenges noted above. Policy debates around the best ways to support the learning and development of our youth as a whole, not just those failing, shifts the debate and opens opportunities for new thinking and action.

Jane Quinn shared one example of how the lack of national policy causes problems in youth work:

The majority of Children's Aid's budget of $\$ 130$ million per year comes from a wide variety of public sources, many of which work in contradiction to one another. The lack of a coherent national youth policy is a problem that affects nearly every funding source. 
National policy is critical to prioritize the needs of young people and to coordinate the goals and efforts of organizations funding, researching, and providing youth services. However, policy is insufficient on its own. Jack Kosakowski noted that a federal policy would still fail to address local policy challenges in specific areas, such as work readiness:

The challenge with national policy approaches in the United States is that $K-12$ plays a critical role in work readiness and $K-12$ policy is developed to a great extent at the local level. Guidelines at the federal level are often resisted or difficult to implement at the community level.

It will be critical for the advancement of the youth work field to articulate how federal-level initiatives and policies work within local contexts and how local contextualization benefits youth more specifically. As a nation, as local communities, and as professionals, we need to demonstrate the value of youth. Joyce Walker described this need:

We cannot ignore youth who are an undeniable presence in our society. But as a nation and as a field, we share no common agreement of the role of youth in our society. Are they vulnerable victims to be protected? Are they threats to adult society to be controlled? Are they persons whose innovative ideas are nurtured or is the ideal that they are shaped into folks just like us?

The key leaders articulated a need for two paradigm shifts: recognizing the value of youth at a national level, while contextualizing locally and focusing on commonalities among professionals doing youth work.

\section{Fractured Field}

Youth work in practice "is as varied as the settings where it occurs," (Pozzoboni \& Kirshner, 2016; p. 3). There is no one institution that employs youth workers, and there is no one context where youth work takes place (Cooper, 2018). Youth workers in different settings use different models and focus on different outcomes (Pozzoboni \& Kirshner, 2016). Six of the nine key leaders interviewed specifically addressed what Blyth described as, "the multiple and fractured nature of our field." Many leaders called for a movement away from organization-focused practices and paradigms. For example, Blyth states:

As a field we are caught up in making more distinctions, rather than finding common ground and core values around which we can rally, better prepare and support the workforce broadly, and more effectively communicate with the public and decision makers. If we cannot see ourselves as a field and work toward a 
Foundations for the Future

system of opportunities with a well-prepared and intentional workforce, why should others?

While leaders had different opinions about whether the field currently agrees on shared goals or values, the consensus was that we need to agree on overarching principles and move forward in unity. Karen Pittman emphasized how this unified approach will affect youth:

Youth, especially those with the least social and financial capital, are never wellserved by fragmented approaches. Getting agreement on how, where, and when learning and development happens can, at a minimum, create a galvanized understanding of how to think about opportunities and opportunity gaps. Ideally, we can use this understanding to call for better data on access to and quality of opportunities and data on youth's experiences. Only by connecting the dots in a deeper way between opportunities, experiences, and outcomes can we ever reduce the tendency to blame young people and their families for our failures.

Several leaders noted that this division was fueled by competitive funding mechanisms and underfunding of youth work programs. As Blyth shared:

We live in a society that is more competitive for funding than collaborative in understanding and promoting the greater good. We use our values to distinguish what we do from what others do rather than recognize and hold up the common values we do believe in-the value of engaging opportunities, experiential learning, intentional high-quality programs, and well-qualified people to run them.

Siloed organizations cannot serve youth as well as a community with a shared value on youth and some shared approaches in their service. As Walker simply stated, "If we look at the value of programs and organizational contributions, we drift away from youth."

\section{Youth Work Positions Not Valued}

Negative side effects of the lack of national policy and the fractured nature of the field are low salaries and limited support for youth work employees. Two national surveys from 2005 stated the hourly wage of youth workers averaged just $\$ 10.00$, despite more than half of youth workers having a 4-year degree or higher (Yohalem, Pittman, \& Edwards, 2010). According to one inflation calculator, the $\$ 10.00$ wage in 2005 would be roughly equivalent to $\$ 13.48$ in December of 2019 (see: https://data.bls.gov/cgi-bin/cpicalc.pl), which is below the commonly 
discussed standard of a "living wage" of $\$ 15$ per hour. Moreover, less than half of youth workers had access to health insurance through their employer. Although youth workers report high levels of work satisfaction, likely from the intrinsic value of their work with youth, turnover is high and low wages are the most common reason for leaving jobs in youth work. According to youth workers, the most effective ways to improve the youth work field would be to increase wages and offer professional development opportunities (Evans, Sicafuse, Killian, Davidson, \& Loesch-Griffin, 2010).

Key leaders highlighted the critical role that youth workers play in supporting youth, as well as the need to reflect that value in stronger pay and recognition. For example, Pam Garza stated:

With youth as the most significant asset any nation can have, one of the greatest challenges facing the systems that support youth workers remains an attitude and culture towards the significance of this work. Because youth work is neither a consistently acknowledged or appreciated career, organizations continue to strive towards sufficient funds. In addition, since the career is not even recognized, salaries remain low-so low the actual work with youth is not sufficiently paid to support a family. In addition, communications and consistency across the systems is spotty with inconsistent standards.

Quinn added the need for greater support through professional development: A second challenge I see across the field is that the direct-service workers (line staff) are generally the least well-supported among all the staff-a result of the underfunding of programs generally and the perception that there are high rates of turnover among direct-service staff, making it difficult for program administrators to justify the investment in their training and supervision.

\section{Opportunities}

Despite the many challenges facing the field of youth development, key leaders also identified numerous opportunities that forge progress and increase the odds of success. First, there has been growing mainstream $\mathrm{K}-12$ interest in youth work concepts such as social-emotional learning. Practitioners, parents, and policy-makers are increasingly familiar with its concepts and seeking its inclusion both in schools and in youth programs conducted during out-of-school time (Jones \& Doolittle, 2017). In recent decades, there has been substantial growth in the provision and public financing of out-of-school time programs, as well as interest in making 
these programs high-quality (Bodilly \& Beckett, 2005). Pittman described the opportunities relevant to this growth in interest, particularly in social-emotional learning:

As investments in developing trainings/credentials/curricula that address youth's social-emotional skill development and/or increase adults' capacity to create strong relationships/learning environments (e.g. SEL instruction, traumainformed care, restorative justice) grow, we have an opportunity to update and elevate the Positive Youth Development approach as the common denominator.

Second, we have global examples of unified youth platforms to guide our work. The United Nations has developed a global youth policy framework, the World Programme of Action for Youth, and many countries have developed youth policies in adherence with this standard (Chaskin, McGregor, \& Brady, 2018). Ireland, for example, created a comprehensive National Children's Strategy in 2000, established the Department of Children and Youth Affairs to coordinate youth policy, and emphasized youth participation in policymaking (Chaskin et al., 2018). Fusco articulated how we can learn from these examples:

While the same set of economically oppressive policies are occurring around the world, there are also opportunities in understanding youth work globally, especially in contexts that have embraced youth work as a mainstay of their societal condition. In such places, youth work is supported by policy and therefore funding. This creates occupational spaces for worker education, vocational training, and opportunity for advancement, which in turn helps develop a unified language, set of practices, and principles, or at minimum an articulation of differences. Youth policies help create buy-in among the citizenry, which in turn can support programmatic initiatives.

Finally, our field has grown a research base that can provide guiding principles and core competencies. Internationally, governments and funders have focused more on impact and outcomes, and youth work organizations have consequently shifted towards more intervention programs and evidence-based practice (Dunne, Ulicna, Murphy, \& Golubeva, 2014). While some argue that this focus will exclude collaborative, community-based practices, others advocate that the development and use of evidence-based practices can facilitate strong outcomes and increase funding support (Dunne et al., 2014; Li, 2010). Evidence on the effectiveness of positive youth development programming is growing. Though we need more methodologically strong studies, the evidence base demonstrates the effectiveness of programming in academic achievement and psychological adjustment (e.g., Ciocanel, Power, Eriksen, \& Gillings, 2017; 
McCombs, Whitaker, \& Yoo, 2017). This growing evidence base, both in the United States and internationally, allows for the development of guiding principles for the field. The following examples provided by two key leaders demonstrate the research-based development of core competencies, while also highlighting that different organizations still gravitate toward different competencies.

Pittman: The greatest opportunity is that the fundamental premises and principles that undergird youth work support the development of practice expertise linked to increasing the determinants of youth success. UChicago Center on School Research (CCSR) defines these as competencies (broadly defined), integrated identity, and a sense of agency (Foundations of Young Adult Success, 2015) that are now (a) fully affirmed by the science (SOLD with papers available at www. SoLDAlliance.org) and (b) beginning to be accepted by $K-12$ leaders and policymakers.

Hall: National Institute on Out-of-School Time (NIOST) has been working extensively for several years to support cities/states/communities to create core competencies and standards. NIOST gifted the Core Competencies to the National AfterSchool Association. . . . We think we could agree on a core set of values and then, leaving room for specific strategies/language on some of those values or expanded interpretation of those values. We recommend Association for Child and Youth Care Practice (ACYCP) set of core competencies as a model that could align the sectors/fields in that they are global and generic enough.

Fusco noted that more overarching principles may be effective in unifying youth work across different settings.

I have articulated "principles" that my research has found are consistent in youth work practice across a wide variety of contexts and settings (Fusco, 2012). I also, borrowing from international frameworks, have examined youth work "facets" of practice in the U.S. from a historical perspective (Fusco, 2014, 2016). In this way, we can examine the various goals of youth work over time and how those have shifted. 
A good next step for the development of the field of youth work would be to draw on these principles and competencies and to use them in unifying our perspectives and setting overarching objectives.

\section{Effective Strategies and Successes}

Each of the key leaders identified current effective strategies and success stories that can potentially be generalized to address profession-wide challenges and move the field forward. Strategies included the development of credentialing programs, agreement on core youth work values by drawing from the current science base, partnering across sectors, and valuing the youth worker. Each suggested strategy is detailed below.

\section{Agreement on Core Values}

Internationally, one of the first areas of focus of national youth policy frameworks is to establish shared priorities and values of the youth work (Dunne et al., 2014). This step is necessary to unify efforts and partners. All leaders agreed that shared values would break down silos and move the field forward as a unified entity. Blyth described how this would require ongoing commitment:

I believe we can and must [agree on core values] for real progress as a field. It will take more than a convening and a report to do so. We need to create unifying or gravitational forces that pull us together rather than allow the centrifugal forces operating to keep pulling us in separate directions.

A research base exists to inform this endeavor. As Pittman stated, "Can we agree on a core set of values? Yes, but our (The Forum for Youth Investment's) recommendation is that we can do this faster and with more authority if we work from the science, not from our personal or organizational histories."

Stephanie Hull described the potential future value of shared goals: Having a set of clearly defined goals would help the youth development field strengthen the support system for youth workers, in turn improving outcomes for youth. With goals standardized across the field as a whole, organizations can be held accountable for meeting measurable objectives, yielding better outcomes for young people. It is crucial to know what the intended outcomes are in order to evaluate whether or not a program or policy makes a difference in the lives of youth. This shared approach would also support collaboration across various 
Foundations for the Future

organizations and youth-serving fields, as organizations and subfields within youth development could more readily share best practices, resources, and ideas about how to reach these shared goals.

Such values must include all youth. Quinn described this need:

I want to emphasize, here and elsewhere, my major concern about equity. When I worked on A Matter of Time: Risk and Opportunity in the Nonschool Hours (the Carnegie report that was published in December of 1992), we documented from the evidence available then that low-income youth and youth of color had far fewer opportunities than more affluent white youth to participate in high-quality youth development programs. This opportunity gap has turned out to be a very persistent one, despite some new public investments (such as $21^{\text {st }}$ Century Community Learning Centers). We need better data to be able to investigate these equity issues.

Both agreeing on core values and partnering across sectors to advance those values will be necessary to work towards coherent public policy and increased funding.

\section{Credentialing Programs}

Strong credentialing programs elevate the field and support current youth workers. While a small number of higher education programs supporting youth work began in the 1980s, there has been a recent increase in the number of youth development credentialing programs (e.g., Foundations, Inc.; National Afterschool Association; After-School Corporation, Inc.). Youth workers who participate in credentialing programs report positive outcomes in professionalism, organizational practices, and community engagement (Garst, Weston, Bowers, \& Quinn, 2019; Richmond et al., 2016). Pittman described the focus of an emerging partnership with the University of Pittsburgh's School of Education as investing in graduate fellows to help us shape a future meeting on the allied youth work workforce, defining an ongoing research agenda, and creating a new credentialing and master's degree program focused on providing more targeted, youth- and community-centric training to these leaders.

There has also been a call for research on youth practitioner expertise to better understand challenges and effective practice from the youth practitioners' perspective (Larson, Walker, 
Rusk, \& Diaz, 2015). Joyce Walker described the role of academic programs in supporting community workers and in drawing from practitioner wisdom:

Over the last 20 years, the Center for Youth Development at the University of Minnesota has worked in partnership with state agencies, community networks, foundations and youth practitioners to build cohesion, shared knowledge and advocacy among youth workers in the field. The practitioner professional development and field-building falls roughly into five areas: an academic degree program, a youth worker fellowship, production of e-study modules derived from practitioner wisdom, a series of youth work history conferences, and publication of journal articles giving voice to practice dilemmas and wisdom.

\section{Partnership Across Sectors}

Partnership across organizations is paramount to the unification and advancement of the field of youth development. This is reflected in the first goal of the IWGYP's strategic plan for federal collaboration, which is to promote coordinated strategies to improve youth outcomes (IWGYP, 2016). IWGYP (2016) notes that "the most vulnerable youth face multiple challenges that do not fit into traditional categorical ('siloed') programs," and programs must partner and collaborate smoothly to serve the youth at most risk (p. 15). Hall listed several techniques that would break down silos, including

- partnership work on tools that can be used across sectors-not necessarily creating new tools but gaining support to field-test and utilize some of the existing tools across sectors

- broad work across partners on system-building that stretches across all of these sectors in city demonstration sites

- building the cross-sector city work in the same way we have worked on system-building within each of the sectors

The following are concrete examples demonstrating how these partnerships can be established: Walker: Now as a citizen volunteer, I work with the NorthStar Youth Practitioner Fellowship which is designed to democratize the field of youth work as mid-level practitioners gather to reflect on their practice with a cohort of peers, work together on problems or practice dilemmas, and produce a paper for sharing and publication. This model has evolved over 10 years after early participation in an Afterschool Matters pilot project led by Sarah Hill. We are organized by volunteers, exist on a very low budget, and really nurture the innovative ideas 
Foundations for the Future

and practice wisdom of these growing community leaders. Some small groups have also developed e-study training modules on topics like rights-based youth work and strategies for youth-centered practice. (These e-study modules are free and distributed through The Hubert Project at the University of Minnesota's Humphrey Institute).

Pittman: One example of partnership is the work with youth development leaders across the country who were a part of the National Commission on Social, Emotional, and Academic Development's (SEAD) Youth Development Work Group to create a sustainable plan for coordinating and expanding efforts. Our goal is to ensure that the Commission's work (and the related work of the SOLD Alliance, the National Academy of Medicine, etc.) is (a) fully leveraged by these leaders and (b) informed by, if not linked to, $K-12$ efforts as much as possible.

To create these partnerships, a leader or director is needed. Hall noted that we "need funder leadership to help establish this path of work [that can be used across sectors]."

Garza provided examples of how this can function:

I think one of the best models I have seen is when a major funder (or group of funders) supports youth issues and, in addition to funding one individual organization (multiple organizations), funds an organization to oversee the gathering of information and dissemination of learning and issues across the field. In addition, the funder convenes the organizations to learn from each other and pays for additional resources and thinking to continue to maximize on the investment in youth. The funder also does multiple-year funding that enables thinking, building and sustaining of promising practices.

Quinn and Hall both suggested federal-level coordination.

Quinn: I would like to see the re-establishment of the White House Conferences on Children and Youth. When they existed (I think the last one was held in the early 1970's), they produced important policy-relevant reports and other documents, and they served to direct national attention to the current state of young people's well-being. Now, more than ever, we need to examine both the state of America's young people and the current state of knowledge about what our society could do to make much-needed improvements. 
Kosakowski, in contrast, suggested connecting with community leaders at a local level, stating "There is probably more value in engaging community leaders and then sharing best practices through networking organizations, such as Chambers of Commerce, Conference of Mayors, and professional associations for educators."

As mentioned earlier, there would be a great deal of value in contextualizing national-level policy and initiatives within local situations to best serve youth in each community and across communities.

\section{Valuing the Youth Worker}

Valuing youth workers through training, support, and compensation ensures that our field will have strong leaders and youth will have strong mentors. Youth workers themselves report the most effective ways to improve the youth work field would be to increase wages and offer professional development opportunities (Evans, W. P. et al., 2010). Yohalem et al. (2010) suggest that small increases in wages may increase staff retention.

Several key leaders shared examples of ways to value and support youth workers. Hull described how Girls Inc. designed a professional development program to support their staff as professionals:

Although a commitment to continuous learning is best practice, a recent 4-H study found that most professional development opportunities for program staff were one-time and episodic, and that these more traditional forms of professional development, such as group-based, one-off trainings, were less effective than ongoing opportunities. This study also mentions that while learnercentered trainings and opportunities for youth workers to learn from one another are more effective, these opportunities were offered to program staff less frequently. It is important that youth workers feel supported in their growth as professionals, have a pipeline for advancement, and can develop leadership skills, which in turn will allow them to be more effective in delivering programs that have measurable positive outcomes for young people. . . . This year Girls Inc. is launching a learning strategy that outlines the ways in which the network will provide and build its capacity for professional development. Part of this strategy includes a new learning management system (LMS), which will house courses, learning assets, webinars, virtual trainings, and an informal social 
learning platform. The LMS will provide staff with on-demand information, training, interaction, and professional development opportunities that prepare them to implement high-quality programming and build meaningful mentoring relationships with the girls they serve.

Quinn described how Children's Aid tailored educational support for their direct staff, including both part- and full-time staff:

At Children's Aid, we made an organizational decision to invest in direct-service staff (line workers) in our after-school and summer programs. This is an artifact, in part, of being a relatively well funded organization and also the result of advocacy on the part of organizational leaders, myself included. We invested in day-long staff development trainings twice each year, and we paid our part-time staff to participate. For the summer programs (Children's Aid runs 25 summer camps each year), we also invested in extensive orientation and training before the start of the summer programming. We built training and supervision costs into our grant applications as a way to educate funders that we saw these as a cost of doing business. We also took advantage of training opportunities outside Children's Aid-for example, through the Partnership for After School Education, an intermediary based in NYC.

Garza gave an example of how organizations can provide stronger compensation and support systems:

Many organizations are addressing the challenges and opportunities for youth workers. In just one case with the organization that I am currently doing consulting with, NatureBridge, they have been reviewing and updating their entire educator compensation systems. This includes not only their salaries, but also an expectation of competencies, their learning systems, their coaching systems and support systems. This small organization provides a glimpse into the opportunity for all organizations, whether large or small, that work in one or more than one site.

While these steps are necessary to support both our youth workforce and the youth they serve, Hull clarified that workforce supports must be accompanied by recruiting youth workers who represent the cultures and backgrounds of the youth served.

Supporting a youth workforce that reflects the diversity of the youth served is important for providing these [physically and emotionally safe] spaces and 
Foundations for the Future

positive outcomes for youth. With this commitment to diversity in mind, Girls Inc. is interested in strategies and resources for recruiting, retaining, and investing in the professional development of staff and volunteers who represent the communities and identities of the girls it serves.

\section{Put Youth at the Center}

We end by echoing the clarion call of many youth leaders that youth must remain the central focus of all youth work and policy setting. Given that positive youth development focuses on young people's skills and abilities, we must attend to the contributions of youth themselves (Leman et al., 2017) to our programs and our field. Youth-led initiatives can lead to new programs, policy change, and institution building that strengthen the community (Christens \& Dolan, 2011).

Walker described how the central assumptions of positive youth development described throughout this issue must be carried out in our field: "I believe it begins with youth rightsyoung people being valued as important, innovative, positive human beings who have the right to speak up on issues of self, relationships, community, and fairness." Fusco described why we must facilitate youth voice in policy:

A youth work policy, like any policy, will be effective for the field only if it is representative of the various voices and positions of young people and their communities, beyond tokenism! "Youth" as a socially constructed category rests on ageist assumptions that young people have had no role in crafting. In my opinion, then, any youth policy should challenge those assumptions. Young people who represent a wide variety of communities across the country should be at the table on the policy. A democratic process of the development and implementation of that policy is critical.

Finally, Garza described the successes that are already happening as organizations prioritize youth:

I do believe that collaborations that can put youth first can make a difference in the work that is done with and on behalf of youth. Whether it is the National Collaboration for Youth, Ready By 21, Strive, STEM Ecosystems, Next Generation Youth Work Coalition, etc. - whether they still exist or served a role at the moment of development, these coalitions, collaborations, etc. work on the 
Foundations for the Future

thornier issues and bring them forward, test strategies, create a forum across sectors, and build relationships between colleagues in the field beyond the organization, the coalition, or the current trendy funding or issue.

Taken together, this special issue offers insights into challenges and opportunities across the field of youth development. The profession has much to offer, but without a unifying, clear identity and direction that bring cohesion to its disparate parts, it risks being disregarded or absorbed into another field. Pittman (2018) notes, "As a call for better integration of social and emotional learning into the school building and school day takes hold. . . . My concern is that we are simply not seen as knowledge partners because they do not know that our research exists and could and should inform their practice" (pg. 3). As a field, we must actively engage in building the field of youth development so that knowledge and expertise within can be disseminated across other fields. This will require a dedicated effort to involve all sectors of the field to identify the key practices and principles of youth development. In addition, youth work professionals must be recognized for their knowledge, skills, and experience and be rewarded for them. Researchers and practitioners must also continue to publish their work to serve as a foundation for the field off of which others can build. In doing so, youth development will have the chance to become a dynamic and integrated field that is home to many.

\section{References}

Benson, P. L., \& Pittman, K. (Eds). (2001). Trends in youth development: Visions, realities, and challenges (Outreach scholarship, Vol. 6). Boston, MA: Springer. https://doi.org/10.1007/978-14615-1459-6

Barton, W. H., \& Butts, J. A., (2008). Building on strength: Positive youth development in juvenile justice programs. Chicago, IL: Chapin Hall Center for Children at the University of Chicago.

Bodilly, S., \& Beckett, M. K. (2005). Making out of school time matter: Evidence for an action agenda. Santa Monica, CA: RAND.

Borden, L. M., Schlomer, G.L., \& Wiggs, C. B. (2011). The evolving role of youth workers. Journal of Youth Development, 6(3). https://doi.org/10.5195/jyd.2011.179

Chaskin, R. J., McGregor, C., \& Brady, B. (2018). Supporting youth civic and political engagement: Supranational and national policy frameworks in comparative perspective. Galway, Ireland: UNESCO Child and Family Research Centre. http://www.childandfamilyresearch.ie/media/unescochildandfamilyresearchcentre/Full-Report1.pdf 
Christens, B. D., \& Dolan, T. (2011). Interweaving youth development, community development, and social change through youth organizing. Youth \& Society, 43(2), 528-548. https://doi.org/10.1177/0044118X10383647

Ciocanel, D., Power, K., Eriksen, A., \& Gillings, K. (2017). Effectiveness of positive youth development interventions: A meta-analysis of randomized controlled trials. Journal of Youth and Adolescence, 46(3), 483-504. https://link.springer.com/article/10.1007/s10964-016-0555-6

Cooper, T., (2018), Defining youth work: Exploring the boundaries, continuity and diversity of youth work practice. SAGE Handbook of Youth Work Practice, 3-17, London, Sage.

Dunne, A., Ulicna, D., Murphy, I., \& Golubeva, M. (2014). Working with young people: the value of youth work in the European Union. Brussels: European Commission.

Evans, D. L., Foa, E. B., Gur, R. E., Hendin, H., O’Brien, C. P., Seligman, M. E. P., \& Walsh, B. T. (Eds.) (2005). The positive perspective on youth development. In Treating and preventing adolescent mental health disorders: What we know and we don't know. A research agenda for improving the mental health of our youth. New York, NY: Oxford Press. https://doi.org/10.1093/9780195173642.003.0027

Evans, W. P., Sicafuse, L. L., Killian, E. S., Davidson, L. A., \& Loesch-Griffin, D. (2010). Youth worker professional development participation, preferences, and agency support. Child \& Youth Services, 31(1-2), 35-52. https://doi.org/10.1080/01459350903505579

Fusco, D. (2012). Advancing youth work: current trends, critical questions. New York: Routledge.

Fusco, D. (2014). The social architecture of youth work practice. In B. Belton (Ed.), 'Cadjan-Kiduhu' global perspectives on youth work (pp. 47-60). Rotterdam: Sense. https://doi.org/10.1007/97894-6209-767-4_3

Fusco, D. (2016). History of youth work: Transitions, illuminations and refractions. In M. Heathfield \& D. Fusco (Eds.), Youth and inequality: Global actions in youth work (pp. 36-52). NY: Routledge.

Garst, B. A., Weston, K. L., Bowers, E. P., \& Quinn, W. H. (2019). Fostering youth leader credibility: Professional, organizational, and community impacts associated with completion of an online master's degree in youth development leadership. Children and Youth Services Review, 96, 1-9. https://doi.org/10.1016/j.childyouth.2018.11.019

Halpern, R. (2002). A different kind of child development institution: The history of after-school programs for low-income children. Teachers College Record, 104(2), 178-211.

Interagency Working Group on Youth Programs. (2016). Pathways for youth: Strategic plan for federal collaboration. https://youth.gov/sites/default/files/IWGYP-Pathways for Youth.pdf

Jones, S. M., \& Doolittle, E. J. (2017). Social and emotional learning: Introducing the issue. The Future of Children, 271), p. 3-11. https://www.wallacefoundation.org/knowledge-center/Documents/FOCSpring-Vol27-No1-Compiled-Future-of-Children-spring-2017.pdf 
Larson, R. W., Walker, K. C., Rusk, N., Diaz, L. B. (2015). Understanding youth development from the practitioner's point of view: A call for research on effective practice. Applied Developmental Science, 19(2), 74-86. https://doi.org/10.1080/10888691.2014.972558

Leman, P. J., Smith, E. P., Petersen, A. C., \& SRCD Ethic-Racial Issues and International Committee. (2017). Introduction to the special section of Child Development on positive youth development in diverse and global contexts. Child Development, 88(4), 1039-1044. https://doi.org/10.1111/cdev.12860

Li, J. (2010). Hours of Opportunity (Research brief). Santa Monica, CA: RAND. https://www.rand.org/pubs/research briefs/RB9551z1/index1.html

McCombs, J., Whitaker, A., \& Yoo, P. (2017). The value of out-of-school-time programs. Santa Monica, CA: RAND. https://www.rand.org/pubs/perspectives/PE267.html

Pozzoboni, K. M., \& Kirshner, B. (Eds.) (2016). The changing landscape of youth work: Theory and practice for an evolving field. Charlotte, NC: Information Age.

Richmond, A., Brown, S., Braughton, J., Otto, M., Roeske, R., Jaeger, E., . . Borden, L. M. (July, 2016). Youth workers' professional development: The importance of youth development certificate programs. Report Submitted to the U.S. Department of Defense, Washington, DC.

Walker, J. A., Walker, K. C., \& Gambone, M. A. (2011). Reflections on a century of youth development research and practice. Journal of Youth Development, 6(3). https://doi.org/10.5195/jyd.2011.172

Yohalem, N., Pittman, K., \& Edwards, S.L. (2010). Strengthening the youth development/afterschool workforce: Lessons learned and implications for funders. Washington, DC: The Forum for Youth Investment. 